\title{
O palhaço como força inspiradora no enfrentamento do processo de hospitalização em pediatria e hebiatria
}

\author{
The clown as an inspiring force in facing the hospitalization process in pediatrics and hebiatry \\ El payaso como fuerza inspiradora en el enfrentamiento del proceso de hospitalización en pediatría \\ y hebiatría
}

Recebido: 12/01/2021 | Revisado: 13/01/2021 | Aceito: 18/01/2021 | Publicado: 22/01/2021

Mayara de Oliveira Walter

ORCID: https://orcid.org/0000-0002-3536-4897

Hospital Regional do Oeste, Brasil

E-mail: mayarawalter14@gmail.com

Crhis Netto de Brum

ORCID: https://orcid.org/0000-0002-2970-1906 Universidade Federal da Fronteira Sul, Brasil E-mail: crhis.brum@uffs.edu.br

Tayná Bernadino Coutinho

ORCID: https://orcid.org/0000-0001-6082-6232 Universidade Federal da Fronteira Sul, Brasil

E-mail: taynabercoutinho@gmail.com

Caroline Sbeghen de Moraes

ORCID: https://orcid.org/0000-0003-3730-2486

Universidade Federal da Fronteira Sul, Brasil

E-mail: carolinesbeghendemoraes@gmail.com

Samuel Spiegelberg Zuge

ORCID: https://orcid.org/0000-0002-0420-9122

Universidade Comunitária da Região de Chapecó, Brasil

E-mail: samuel.zuge@ unochapeco.edu.br

Camila Olinda Giesel

ORCID: https://orcid.org/0000-0001-9063-5322

Universidade Federal da Fronteira Sul, Brasil

E-mail: camilagiesel@gmail.com

Vitoria Pereira Sabino

ORCID: https://orcid.org/0000-0002-0039-9571 Universidade Federal da Fronteira Sul, Brasil

E-mail: vitoria.sabino31@ outlook.com

Susane Dal Chiavon

ORCID: https://orcid.org/0000-0001-5656-7397 Universidade Federal da Fronteira Sul, Brasil

E-mail: susanepzo@gmail.com

Patricia Aparecida Trentin

ORCID: https://orcid.org/0000-0002-9051-7657

Hospital Regional do Oeste, Brasil

E-mail: patricia01trentin@ hotmail.com

Ana Lúcia Lago

ORCID: https://orcid.org/0000-0003-0758-3790

Universidade Comunitária da Região de Chapecó, Brasil

Universidade Federal da Fronteira Sul, Brasil

E-mail: analago@unochapeco.edu.br

\begin{abstract}
Resumo
Objetivo: Compreender a percepção criança, do adolescente e do cuidador familiar sobre a presença do palhaço durante o processo de hospitalização. Metodologia: estudo qualitativo, descritivo exploratório com 20 participantes, sendo cinco crianças, cinco adolescentes e 10 cuidadores familiares que vivenciaram o processo de hospitalização em um hospital pediátrico no Oeste de Santa Catarina, realizado entre agosto e outubro de 2019. A produção dos dados contou com entrevistas. A análise de dados ocorreu concomitante à etapa de campo e foi em conformidade com a análise de conteúdo proposta por Bardin. Resultados: Emergiu três categorias temáticas: O palhaço como força inspiradora para enfrentar as dificuldades causadas pelo processo de hospitalização: quando você está feliz tudo começa a fluir melhor; a busca de estratégias para a ressignificação da hospitalização: tem que respirar e enfrentar e o palhaço como mediador entre o processo de hospitalização e o contexto da vida anterior: Eu daria tudo para estar lá em casa. Considerações finais: A realização deste estudo possibilitou a compreensão de que a presença do
\end{abstract}


personagem palhaço no processo de hospitalização minimiza os impactos da internação com a oferta de elementos lúdicos que auxiliam na recuperação.

Palavras-chave: Enfermagem; Criança; Adolescente; Hospitalização; Ludoterapia.

\begin{abstract}
Objective: Understand the perception of children, adolescents and family caregivers about the presence of the clown during the hospitalization process. Methodology: qualitative, descriptive exploratory study with 20 participants, five children, five adolescents and 10 family caregivers who experienced the hospitalization process in a pediatric hospital in the West of Santa Catarina, held between August and October 2019. The production of the data included interviews. The data analysis occurred concomitant to the field stage and was in accordance with the content analysis proposed by Bardin. Results: Three thematic categories emerged: The clown as an inspiring force to face the difficulties caused by the hospitalization process: when you are happy everything starts to flow better; the search for strategies for the re-signification of hospitalization: has to breathe and face and the clown as mediator between the hospitalization process and the context of the previous life: I would give anything to be there at home. Conclusion: The performance of this study enabled the understanding that the presence of the clown character in the hospitalization process minimizes the impacts of hospitalization with the offer of playful elements that help in recovery.
\end{abstract}

Keywords: Nursing; Children; Adolescent; Hospitalization; Play therapy.

\title{
Resumen
}

Objetivo: Comprender la percepción del niño, del adolescente y del cuidador familiar sobre la presencia del payaso durante el proceso de hospitalización. Metodología: estudio cualitativo, descriptivo exploratorio con 20 participantes, siendo cinco niños, cinco adolescentes y 10 cuidadores familiares que experimentaron el proceso de hospitalización en un hospital pediátrico en el Oeste de Santa Catarina, entre agosto y octubre de 2019. La producción de datos contó con entrevistas. El análisis de datos se llevó a cabo simultáneamente la etapa de campo y fue en conformidad con el análisis de contenido propuesto por Bardin. Resultados: Emergieron tres categorías temáticas: El payaso como fuerza inspiradora para enfrentar las dificultades causadas por el proceso de hospitalización: cuando usted está feliz todo comienza a fluir mejor; la búsqueda de estrategias para la resignificación de la hospitalización: tiene que respirar y enfrentar y el payaso como mediador entre el proceso de hospitalización y el contexto de la vida anterior: Daría todo por estar en casa. Conclusión: La realización de este estudio ha permitido la comprensión de que la presencia del personaje payaso en el proceso de hospitalización minimiza los impactos de la internación con la oferta de elementos lúdicos que auxilian en la recuperación.

Palabras clave: Enfermería; Niño; Adolescente; Hospitalización; Ludoterapia.

\section{Introdução}

O processo de hospitalização de crianças e adolescentes é marcado por insegurança e desconforto combinados à anseios e medos, estes, relacionados ao afastamento do cotidiano familiar e escolar, inserção em um ambiente regrado e hostil, procedimentos técnicos por vezes dolorosos, configurando a hospitalização como uma experiência traumática (Gonçalves, Figueiredo, Oliveira, Darvim, Camboim \& Camboim, 2017).

Em razão da modificação abrupta da rotina da criança e/ou adolescente e sua família, há uma demanda de adaptação dos envolvidos com o ambiente hospitalar e seu cotidiano, bem como com os procedimentos invasivos. A internação infantil gera um grande impacto emocional e o surgimento de sentimentos como insatisfação, estresse, tristeza, ansiedade e agressividade são recorrentes (Silva, Monteiro, Coutinho, Cruz, Araújo, Dias \& Costa, 2020).

Dessa forma, têm-se no lúdico uma ferramenta importante com potencial de minimizar os impactos da hospitalização. O uso do lúdico intensifica o processo de adaptação, favorecendo interação entre equipe multiprofissional, criança e/ou adolescente e sua família, deixando o ambiente mais agradável e descontraído, auxiliando também no processo saúde-doença e hospitalização (Marques, Garcia, Anders, Luz, Rocha \& Souza, 2016).

Portanto o lúdico coopera para a produção a autonomia criativa, para o desenvolvimento da comunicação, para a valorização da subjetividade e para a liberdade de expressão do sujeito, pode ser uma relevante estratégia a ser utilizada no cuidado de enfermagem, visando uma melhor adaptação das crianças, dos adolescentes e suas famílias ao processo terapêutico e um melhor enfrentamento às suas condições de saúde (Moraes, Sabino, Coutinho, Giesel, Brum, Trentin, Walter, Zuge \& Lago, 2020). 
Neste cenário as práticas terapêuticas advindas da ludicidade, como por exemplo a palhaçaria, estimulam a autonomia de crianças e adolescentes que vivenciam o processo de hospitalização. A intervenção da palhaçaria resgata o brincar no cuidado da criança e do adolescente, favorecendo relaxamento, diversão, expressão de sentimentos, facilitando a adaptação à rotina hospitalar, adesão aos tratamentos e consequentemente oportuniza um processo de hospitalização mais alegre e menos traumático (Moraes et al., 2020; Ribeiro, Coutinho, Eduardo, Neto, Pereira \& Costa, 2020)

Em ambiente hospitalar a figura do palhaço associado ao brincar, acentua as relações humanas entre profissionais, pacientes e cuidadores familiares, impulsionando a constituição do vínculo e a confiança da pessoa hospitalizada. Além de proporcionar conforto e beneficiar a expressão e a comunicação (Moura Júnior, Godoy \& Medeiros, 2018.). Compreende-se que a figura do palhaço integra as práticas de cuidado entre os profissionais e as crianças e/ou adolescentes, reorganizando as relações de quem cuida e de quem é cuidado (Moraes et al., 2020).

Assim, buscando artefatos que possam munir os profissionais da área da saúde na busca pelo lúdico para um cuidado humanizado em pediatria e hebiatria, emergiu a seguinte questão de pesquisa: qual a percepção sobre a presença do palhaço durante o processo de hospitalização? E como objetivo: Compreender a percepção criança, do adolescente e do cuidador familiar sobre a presença do palhaço durante o processo de hospitalização.

\section{Metodologia}

Trata-se de um estudo de abordagem qualitativa, descritiva exploratória com 20 participantes, sendo cinco crianças, cinco adolescentes e 10 cuidadores familiares que estavam vivenciando o processo de hospitalização em um hospital pediátrico no Oeste de Santa Catarina realizado entre agosto e outubro de 2019.

Foram incluídos no estudo crianças, adolescentes e cuidadores familiares. Para a definição etária foi utilizado o Estatuto da Criança e do adolescente que define criança de zero a nove anos de idade completos e adolescente de 10 a 19 anos de idade completos. Foi considerado cuidador familiar independente do laço sanguíneo, enquanto estavam acompanhando a criança e/ou adolescente no decorrer do processo de hospitalização. O conceito de cuidador familiar utilizado neste estudo é aquele que transfere para si as tarefas de realização das atividades diárias do paciente, nem sempre possuem laços sanguíneos, mas podem ter laços afetivos. Para isso, ao iniciar a pesquisa era perguntado como o participante se reconhecia no cuidado junto a criança ou adolescente (Valandro, Brum, Potrich, Gaio, Moraes, Sabino, Berlanda, Coutinho, Gadonski, Chiavon \& Albani, 2020). Os critérios de exclusão foram: Crianças ou adolescentes em condição de isolamento hospitalar ou sem liberação médica para receber visitas, cuidadores formais.

A etapa de produção de dados foi seccionada em dois momentos: 1) aproximação e ambientação com o cenário de pesquisa: definido pela realização de uma aproximação com o cenário da pesquisa, denominada como ambientação, momento de (re)construir relações e buscar o (re)conhecimento com a unidade de saúde (Brum, Paula, Padoin \& Zuge, 2016) permitindo estabelecer um contato com os participantes da pesquisa e da rotina do serviço de saúde.

No segundo momento, foi explicado o estudo para os responsáveis pela criança ou adolescente, o qual assinaram o Termos de Consentimento Livre e Esclarecido (TCLE) que foi assinado em duas vias de igual teor. Após o aceite do responsável, dirigiu-se a criança ou adolescente para explicitar sua participação, foi mencionado que seu cuidador assentiu sua participação e, em seguida, foi apresentado o Termo de Assentimento Livre e Esclarecido (TALE) que foi assinado em duas vias de igual teor, o qual estava organizado a partir de uma história em quadrinhos. Tendo seu aceite a partir da manifestação, entre sim ou não desenhado no TALE, iniciava o estudo. Para o cuidador familiar foi apresentado o TCLE que, também, foi assinado em duas vias de igual teor.

Para as crianças e adolescentes foi realizada uma entrevista semiestruturada por meio de questões norteadoras para a produção de um desenho. Sendo assim, as questões foram organizadas da seguinte forma: 1) Por que você está aqui? 2) Como 
você se sente aqui no hospital? 3) Gosta dos palhaços? 4) Se você recebesse uma visita de um palhaço, como seria para você? O gravador foi ligado após o consentimento da criança ou adolescente em participar da pesquisa. Durante o desenho não houve diálogos a fim de possibilitar a criança ou adolescente a refletir acerca do que foi questionado. Após a confecção dos desenhos, era solicitada a sua explicação.

Para o cuidador familiar foi realizada uma entrevista semiestruturada com as seguintes questões: Como você vê o processo de hospitalização do seu filho/a? Como você vê a entrada de palhaços? Também foi coletado as seguintes informações: Sexo; Data de nascimento e qual tipo de vínculo que possuía com a criança ou adolescente

As entrevistas foram audiogravadas e, posteriormente, transcritas integralmente, após cada entrevista. Para manter o sigilo dos dados dos participantes, estes receberam um codinome, que foi identificado pelo próprio participante da pesquisa.

A análise de dados ocorreu concomitante à etapa de campo e foi em conformidade com a Análise de Conteúdo proposta por Bardin (2016), a qual propõe três fases: pré-análise; exploração do material e tratamento dos resultados obtidos e interpretação. Logo, emergiu três categorias temáticas: O palhaço como força inspiradora para enfrentar as dificuldades causadas pelo processo de hospitalização: quando você está feliz tudo começa a fluir melhor; a busca de estratégias para a ressignificação da hospitalização: tem que respirar e enfrentar e o palhaço como mediador entre o processo de hospitalização e o contexto da vida anterior: Eu daria tudo para estar lá em casa.

A pesquisa respeitou as normas e diretrizes da Resolução número 466 de 2012 (Brasil, 2012) e recebeu aprovação do Comitê de ética e pesquisa com seres humanos da Universidade Federal da Fronteira Sul, Campus Chapecó sob parecer número 3.276.954.

\section{Resultados e Discussão}

O palhaço como força inspiradora para enfrentar as dificuldades causadas pelo processo de hospitalização: quando você está feliz tudo começa a fluir melhor

A expressão utilizada 'quando você está feliz, tudo começa a fluir melhor' foi proveniente da fala de uma mãe cuidadora familiar durante a entrevista, onde utilizou a expressão para descrever a presença do palhaço no contexto de hospitalização. Afirmou que o palhaço faz com que as crianças e adolescentes e seus familiares tenham uma sensação de força e bem-estar. 'Quando você está feliz' representa o contexto de uma fuga da realidade causada pela ludicidade demonstrada pelos elementos que compõem o personagem do palhaço como fantasias coloridas e extravagantes, maquiagem, nariz vermelho, apresentações teatrais, jogos e outros que evocam sentimentos de conforto, que os entrevistados demonstram como satisfação, alegria ou riso.

No entanto, a fala 'tudo começa a fluir melhor' baseia-se no fato de que os sentimentos provocados pela visita do palhaço amenizam as difíceis vivências do processo de hospitalização, fazendo com que as contingências pareçam mais simples para algumas crianças e adolescentes. Reconduzindo, inclusive, a relação dialógica para a presença do palhaço, despertando experiências de memórias com personagens e fantasias relacionadas a jogos e lazer.

Considerando que o hospital representa o processo de recuperação da saúde, há que se buscar estratégias para a enfrentamento da mecanização do cuidado que ocorre de forma desenfreada diante da mercantilização da saúde, de tal maneira que a busca da humanização do cuidado e dá reconhecimento da idiossincrasias de cada a arte se manifesta como instrumento terapêutico promissor no processo de hospitalização, então, como um instrumento de arte e humanização surge a figura do palhaço, que tem participação enérgica na sociedade como propulsor de alegria e riso, auxiliando no combate à ansiedade (Mota, 2020). 
[...] acho muito bom esse trabalho que é feito né na vez passada, quando ele nasceu, eu internei aqui com ele, no dia que ele nasceu, e entrou um palhaço no meu quarto, então, mesmo que ele não entendeu mas eu me senti bem, eu me senti [...] eu não estava nem um pouco feliz mas eu consegui dar um sorriso sabe? Hã é importante isso para a gente, tanto para os pais mas principalmente para as crianças né [...]Eu acho que quando a criança está feliz, o sintoma dela pode né, contribuir para desaparecer, para ela se sentir melhor, mais feliz por que eu acho que felicidade, quando você está feliz tudo começa a fluir melhor né [...]. (Libélula, mãe)

[...] eu acho assim, que o palhaço ajuda muito a criança sabe? Ela vê outras coisas né, fica feliz quando chega assim, distrai, tira o foco da atenção assim. Porque tu fica apreensiva aqui dentro né. Querendo ou não tu fica sempre assim... dai chega alguém diferente que tira teu... Eu acho bom! (Maria, mãe)

[...] eles fazem a gente dar risada e eles são bonitinhos [...] Ia ser legal, porque aí eu poderia ver um palhaço [...] E eles, hã, para as outras pessoas poderia ajudar [...] Se a pessoa estiver doente, assim, com algum problema, ele deixa fazer a gente dar risada. (Betty, adolescente)

[...] Ai foi maravilhoso, foi muito bom [...] Ela riu bastante, ela, até eu ri, o pai dela também tava ali né, tudo né, daí eles fizeram bastante brincadeira daí ele tirou parte da cama, ia levar a cama (risos) [...] Mais para ela é a maior graça que ela achou sabe? coisa mais linda. Isso foi muito bom [...] ajuda que ela se divertiu muito, ajudou ela a se divertir. Ficou muito feliz que nem diz ela [...]. (Polaca, avó)

[...] É que eis são muito engraçado [...] eles rasgam o papel no bolso e vira, uma folha quadrada assim de novo [...] Mas é que eles rasgam e mandam eu assopro e faz uma mágica [...] Daí fica inteiro assim de novo [...]. (Hulk, criança)

O riso é um dispositivo de expressão exclusivo do ser humano, que tem importância indispensável na vivacidade de sentimentos retidos em realidades desordenadas de angústia e desconforto. Por meio do riso o nível de cortisol sérico diminui e o cérebro libera endorfinas, que aliviam a dor e promovem a sensação de bem-estar, sendo que rir proporciona uma respiração mais intensa que facilita as trocas gasosas nos pulmões. Esse analgésico poderoso provedor de sentimentos de euforia e paz, possui um efeito residual que segue agindo no corpo da pessoa que ri (Alcântara, Rossi, Neves, Sabates \& Puggina, 2016).

[...] eles fazem eu rir muito[...]fazem várias mágicas [...] porque eles são engraçados [...] eles fazem coisas que eu, me fazem rir, eu não sei explicar [...] É muito legal e engraçado, eu desenhei um palhaço e eu na cama rindo [...]. (Orquídea, criança)

[...] Ah eu acho bom, ainda mais para as criança maior né que eles se distraem, também até a gente, a gente como pais né, às vezes eles vem fazer visita a gente dá risada, a gente... é um momento de distração né ainda mais pras criança né [...] Ajuda bastante, eles se distraem eles sorri também né, porque tá nesse ambiente também não é fácil né pras criança, nos dão força, ainda mais pra eles né [...] Daí eles, é um pouquinho que eles têm de alegria né [...] Eles têm uma alegria também [...]. (Bella, mãe)

[...] eles são divertidos [...] eles fazem a gente rir também [...] eu ia me acabar de rir [...]. (Sasuque, criança)

[...] Eles são bem legais, são bem engraçados, bem querido [...] Eles... fazem piadas, é, eles fazem gracinha [...] Eu daria bastante risada [...]. (Kira, criança)

[...] eu acho que é um dos projetos mais bonitos que têm [...] a criança fica encantada, porque acha que palhaço é só no circo (risos). daí quando vem no hospital eles bem felizes, e eles brincam, e eles vem [...] eles ficam felizes... eles querem interagir juntos, eles querem fazer [...]. (Bel, mãe)

Para diminuir os fatores traumáticos associados ao adoecimento e à hospitalização, a utilização de atividades lúdicas no cuidado à criança também é uma estratégia humanizadora, visto que a criança possui necessidades emocionais e sociais para o bom desenvolvimento de sua autonomia. O uso dessas ferramentas de cuidado também contribui para o desenvolvimento da cura durante a internação hospitalar, pois a criança expande sua criatividade, se comunica mais e torna-se mais alegre enquanto brinca, o que proporciona melhores condições de recuperação (Souza, Figueiredo, Prado \& Souto 2017). 


\section{Busca de Estratégias de ressignificação da hospitalização: tem que respirar e enfrentar}

Esta categoria foi construída a partir da explicação de um familiar que diante das adversidades 'você tem que respirar e enfrentar', entendeu-se que, diante das dificuldades que a internação pode trazer para a vida de crianças e adolescentes e seus familiares, como distância de casa e da família, afastamento da escola, medidas terapêuticas que podem causar desconforto e até dor, privação da liberdade devido ao diagnóstico e regras de organização hospitalar, entre outros, tem-se nas atividades lúdicas uma possibilidade de ressignificação do contexto. Tanto a criança ou adolescente quanto o cuidador familiar procuram sentar respirar e lidar com a situação caótica (re) significando esse processo por meio da crença de que estar no hospital é o melhor para sua saúde ou para a saúde de sua família.

A hospitalização infantil promove o distanciamento entre a criança e sua família, escola, amigos e demais atividades sociais, além dos sentimentos ocasionados pela doença a torna vulnerável e dificulta seu processo de crescimento. Portanto, o lúdico é um recurso favorável para transformar o ambiente hospitalar em um espaço agradável (Antunes, 2017). Sendo assim, o palhaço pode ser entendido como uma estratégia lúdica que promove a mediação entre o ambiente hospitalar e os fatores indispensáveis no cotidiano de crianças e adolescentes.

[...] enquanto eles estão aqui eles estão sendo bem cuidados né, é [...] isso é difícil, mas necessário, a gente sabe que estando aqui ele tá bem cuidado. É muito importante estar aqui [...] eles dão bastante atenção para a gente, estão sempre no quarto pedindo se precisa alguma coisa e avaliando o estado de saúde do, da criança, então por isso é bem bom tá aqui [...] (Libélula, mãe)

[...] Eu gosto das visitas, tipo [...] dos Psicólogos, das Enfermeiras e dos palhaços [...] assim, que fazem a gente dar risada, ver como a gente [...] se a gente está bem [...] (Betty, adolescente)

Acho que a gente tem que respirar e enfrentar né...São coisas que são tão pequenas perto de outras que a gente vê aqui dentro...Então a gente seria até fraco né...perto de outras mais, para nosso caso a gente tem que se fazer forte [...] a gente acaba até criando um vínculo com as pessoas né...querendo ou não convive no mínimo uma semana né, só com elas que daí fica no quarto [...] (Tabita, mãe)

[...] Melhor para minha doença é que fique aqui [...]. Pra mim melhorar [...]. E tem os palhaços. [...] (Hulk, criança)

Adaptação refere-se ao desenvolvimento de estratégias em resposta a situações estressantes, que é um processo que pode ocorrer de várias formas dependendo de variáveis como fatores emocionais e ambientais, entre outros, e pode ter foco emocional ou focado no problema. Normalmente, as famílias que cuidam de crianças hospitalizadas utilizam múltiplas estratégias de enfrentamento, mas há um maior número de estratégias voltadas para a espiritualidade, a própria questão e o apoio social oferecido pelo hospital a outros parentes ou mesmo os pais de outras crianças hospitalizadas. (Azevedo \& Crepaldi, 2018).

[...] os tratamentos que ele recebe que é forte... tudo né, tudo junto, está longe da família... de casa [...]. Fizemos muitos amigos por aqui, uns dão força para os outros. Então daí tipo traz um pouco de alegria para a gente, um pouco de sabe? (o palhaço) tipo a gente fica faceiro de ver eles, é coisa nova, coisa diferente, não é só aqui no hospital, não é só Enfermeiro, não é só Médico né. (Barbie, mãe)

A prática do cuidado dos profissionais da saúde pautada na ludicidade durante a hospitalização da criança e do adolescente, facilita o acolhimento entre ambos os atores desse processo. Além de ser uma prática mais empática e humanizada, o uso do lúdico contribui para um momento de esquecimento da dor provocada pelo contexto da hospitalização (Santos, Silva, Araújo, Lopes \& Caldas, 2019).

\section{O palhaço como mediador entre o processo de hospitalização e o contexto da vida anterior: Eu daria tudo para estar lá em casa}

A frase 'Eu daria tudo para estar em casa' que faz parte desta categoria representa um sentimento expresso de maneiras diferentes pelos entrevistados, marcando o afeto pelo contexto de vida anterior aos acontecimentos que 
desencadearam a hospitalização da criança ou o adolescente, referindo-se à ideia de que neste momento a vida era mais agradável, por outro lado, a mediação provocada pelo palhaço desperta sensações que remetem à alegria de estar em casa.

[...] porque a gente gostaria de estar em casa, eu daria tudo para estar lá em casa com ele né...está no nosso conforto, tá no... e aqui não tem esse conforto né [...]. Ah, você tá lá na tua casa, você toma um chimarrãozinho, você deita no teu sofá, na tua cama... né? ele pode tá lá chorando, precisando do teu apoio, do teu carinho, mas você tá lá com prazer né? aqui é mais difícil, mais complicado né? [...] ai é um momento que vem aquela alegria... de repente eles trazem uma mensagem bacana, alguma coisa que te motiva para você vencer aquela dificuldade que você tá passando, eu acho que é bacana, muito legal eu acho isso, ter os palhaços. (Margarida, família acolhedora)

A inserção dos palhaços no hospital pode incorporar tanto a eficácia do atendimento à criança e adolescente e ao todo que os afeta, quanto a humanização desses aspectos. O palhaço contribui para a remodelação das práticas no ambiente hospitalar, pois retira o foco da doença e as medidas terapêuticas para melhorar a saúde física, uma vez que as oscilações de humor estimuladas pelo palhaço aliviam a dor, afetam a melhora do quadro clínico, influi na recuperação da imunidade, reduz o estresse e propicia no aumento da capacidade de se socializar (Catapan, Oliveira \& Rotta, 2019).

[...] Que é uma forma de distrair ele e de distrair a gente né, porque eles vêm com brincadeira, hã, tipo, cantando música... é uma forma da gente se sentir assim, lembrar do que a gente vivia antes né que tudo era felicidade né, tudo era alegria agora e tipo... têm um pouco mais é menos né? Daí quando eles vêm a gente volta a se sentir bem, fica alegre né? Porque daí eles vêm, cantam, brincam, você esquece um pouco do clima do hospital né? e tudo o que está passando [...] (Barbie, mãe)

[...] eu estava com falta de ar e pneumonia, porque eu estava com dor no pulmão e que estava com muita falta de ar [...]. Eu internei... infelizmente [...] aqui eu sinto muita falta do meu irmão, e da minha mãe [...]. Mas tem os palhaços para ajudar. (Orquídea, criança)

[...] é difícil para gente acompanhar, é difícil estar aqui. Eu tenho um filho que tá em casa, então estou com o coração partido [...] é muito importante porque ã, não é bom tá aqui, a gente tá aqui não é por um motivo bom né, quando tá aqui é porque tem alguma coisa errada né, alguma dor, então isso (os palhaços) contribui bastante né, pros pais e principalmente para as crianças. Eles sim conseguem interagir e ficam felizes né, eu acredito que ajuda e colabora muito com o tratamento deles, eu acho muito importante, acho muito bom e é importante sempre ter eles aqui (os palhaços) deveria ser frequente [...] (Libélula, mãe)

[...] que algumas crianças ficam bastante tristes [...] A, porque eu não estava na minha cidade [...] me machuquei bastante quando eu caí [...]. Os palhaços fazem as crianças se alegrarem. (Kira, criança)

[...] eu estava entrando em coma, daí eles me trouxeram aqui para Chapecó, daí eles me colocaram no soro, daí eles me fizeram injeção [...] eu gosto de comer bastante doce [...] fica só aqui dentro e não tem ninguém pra brinca [...] eu não gosto muito de ficar aqui no hospital porque é ruim [...] é enjoativo...cansaço [...] legal é por causa que eles fazem palhaçada (Adrian, adolescente)

[...] o que eu comia ele comia, meu marido comia [...] às vezes ai vou fazer uma coisa lá em casa, vou escutar uma música que ele gosta, ai a gente... fico pensando, bah ele poderia escutar essa música junto... ele também gosta desse aqui e não vai poder come [...] Ele tá deprimido e coisa e sentindo dor, parece que dá aquele alivio sabe, eles brincam sabe, eles fazem palhaçada, então eu acho muito legal isso, entende? (Cindy, mãe)

[...] eles fazem a gente rir, eles são legal [...] eles são coloridos, eles são bem legal [...] eles fazem piada [...] eu gosto que eles têm aqueles narigão vermelho (Goku, adolescente)

A ludicidade que o palhaço propõe potencializa e favorece um ambiente de imaginação e o desenvolvimento de um novo olhar sobre a realidade usual e contribui para a forma de enfrentar as emoções. Assim, a terapia hospitalar impulsionada pela presença do palhaço é um campo científico que se desenvolveu recentemente, mas que já apresenta resultados bastante significativos no atendimento a crianças e adolescentes (Catapan, Oliveira \& Rotta, 2019). 


\section{Considerações Finais}

A realização deste estudo possibilitou a compreensão de que a presença do personagem palhaço no processo de hospitalização minimiza os impactos da internação com a oferta de elementos lúdicos que auxiliam na recuperação. Para crianças e adolescentes, a presença do palhaço auxilia na (re)significação do processo de adoecimento e hospitalização, promovendo bem-estar e melhorando sua qualidade de vida por meio do riso, mudança de rotina, estímulos e bem-estar no ambiente, inseridos em um contexto, esses momentos são raros. Os cuidadores familiares têm relevância de aumentar a frequência de palhaços no hospital e proporcionar elementos mais lúdicos no cuidado à criança e ao adolescente, como a utilização dessas estratégias pela equipe de saúde durante os procedimentos.

É essencial que os serviços de saúde voltados ao atendimento à pediatria e hebiatria utilizem recursos que transformem esses espaços em ambientes em que a singularidade da criança e do adolescente seja valorizada, oferecendo elementos que fazem parte do seu cotidiano e sensibilizando os profissionais para o preceito de que não há humanização no atendimento de crianças e adolescentes sem a oferta de elementos lúdicos no cuidado.

Destaca-se que a partir desse estudo possam emergir demais possibilidades que premiem avaliações antes e após a inserção do palhaço no âmbito hospitalar. Além disso, torna-se oportuno o desenvolvimento de revisões sistemáticas da literatura que venham a contribuir para o (re)estabelecimento de um cuidado lúdico aliado ao uso da palhaçaria para crianças e adolescentes que vivenciam o processo de hospitalização.

\section{Referências}

Alcântara, P. L., Wogel, A. Z., Rossi, M. I. L., Neves, I. R., Sabates, A. L. \& Puggina, A. C. (2016). Efeito da interação com palhaços nos sinais vitais e na comunicação não verbal de crianças hospitalizadas. Revista Paulista de Pediatria, 34(4), 432-438. https://doi.org/10.1016/j.rpped.2016.02.001.

Antunes, T. S. (2017). Percepção da enfermidade e tratamento a partir da vivência da criança hospitalizada [Trabalho de Conclusão de Curso, Curso de Graduação de Psicologia, Faculdade de Ciências da Educação e Saúde de Brasília]. Centro Universitário de Brasília. https://repositorio.uniceub.br/jspui/bitstream/235/11490/1/21450628.pdf.

Azevêdo, A. V. S. \& Crepaldi, M. A. (2018). Ansiedade e enfrentamento em familiares cuidadores de crianças hospitalizadas com queimaduras. Psicologia Argumento, Curitiba, 92(39), 175-197. http://dx.doi.org/10.7213/psicolargum.36.92.AO03.

Bardin, L. (2016). Análise de conteúdo: edição revista e ampliada (70th ed.).

BRASIL. Resolução n ${ }^{\circ}$ 466, de 12 de dezembro de 2012. Dispõe sobre diretrizes e normas regulamentadoras de pesquisas envolvend o seres humanos. Diário Oficial da República Federativa do Brasil, Brasília, DF, 2013. http://bit.ly/1mTMIS3.

Brum, C. N., Paula, C. C., Padoin, S. M. M., \& Zuge, S. S. (2016). Vivência da revelação do diagnóstico para o adolescente que tem HIV. Texto \& Contexto Enfermagem, Florianópolis, 4(25), 1-6. http://dx.doi.org/10.1590/0104-07072016001760015.

Catapan, S. C., Oliveira, W. F., \& Rotta, T. M. (2019). Palhaçoterapia em ambiente hospitalar: uma revisão de literatura. Ciência \& Saúde Coletiva, 9(24), 3417-3429. http://dx.doi.org/10.1590/1413-81232018249.22832017.

Gonçalves K. G., Figueiredo J. R de, Oliveira S. X., Darvim, R. M. B., Camboim, J. C. A. \& Camboim, F. E. F. (2017). Criança Hospitalizada e Equipe de Enfermagem: Opinião de Acompanhantes. Revista de Enfermagem UFPE online, Recife, 11(Supl. 6):2586-93, junho 2017. 10.5205/reuol.9799-86079-1RV.1106sup201713.

Marques E., Garcia T. M. B, Anders, J. C., Luz, J. H., Rocha, P.K., \& Souza, S. (2016). Atividades lúdicas na atenção à saúde da criança e do adolescente com câncer: perspectivas da equipe de enfermagem. Escola Anna Nery, 20 (3), e20160073. https://doi.org/10.5935/1414-8145.20160073.

Moraes, C. S., Sabino, V. P., Coutinho, T. B., Giesel, C. O., Brum, C. N., Trentin, P. A., Walter, M. O., Zuge, S. S. \& Lago, A. L. A palhaçaria como promotora da saúde no processo de cuidado da criança hospitalizada: um relato de experiência. In: Edson da Silva (Paraná) (org.). Conhecimentos $e$ desenvolvimento de pesquisas nas ciências da saúde, (4a ed.), Atena, https://www.atenaeditora.com.br/post-artigo/42082.

Mota, J. C. S. (2020). Arteterapia, utilizando teatro/clown como terapia auxiliar no tratamento do câncer infantil [Trabalho de Conclusão de Curso do Curso de Graduação em Psicologia, Faculdade Metropolitana de Manaus - FAMETRO. https://www.periodicos.ufam.edu.br/index.php//article/view/7834/5519.

Moura Júnior, M. M., Godoy, B. S. D. \& Medeiros, D. Palhaços-doutores e seus recursos defensivos: um estudo a partir do Questionário Desiderativo. Rev. $S B P H$, Rio de Janeiro, 21(2), 123-144, 2018.

Ribeiro, W. A., Coutinho, V. V. A., Eduardo, C. R. B., Neto, P. F. S., Pereira, B. V. O., Costa, V. S. C. Contributos do brinquedo terapêutico no processo de cuidado a criança hospitalizada: um estudo da literatura. Research, Society And Development, 9(7), 1-19. http://dx.doi.org/10.33448/rsd-v9i7.4706. 
Research, Society and Development, v. 10, n. 1, e43010111894, 2021

(CC BY 4.0) | ISSN 2525-3409 | DOI: http://dx.doi.org/10.33448/rsd-v10i1.11894

Santos, J. M. S. dos, Silva M. E. B., Araújo, R. J. S., Lopes, R. F. \& Caldas, M. A. G. Atividades lúdicas e educação em saúde com crianças hospitalizadas: um relato de experiência projeto resgatar. Gepnews, Maceió, 2(2), 616-623. http://www.seer.ufal.br/index.php/gepnews/article/view/7960/5794.

Silva, J. M. L., Monteiro, A. J. C., Coutinho, E. S., Cruz, L. B. S., Araújo, L. T., Dias, W. B. \& Costa, P. V. D. P. (2020). The instructional therapeutic toy as a tool in child cancer care. Research, Society and Development, 9(7):1-14. 10.33448/rsd-v9i7.4253. URL: https://rsdjournal.org/index.php/rsd/article/view/4253.

Souza, A. A. M., Figueiredo, M. L., Prado, P. F., \& Souto, S. G. T. (2017). Uso de recursos lúdicos na assistência à criança hospitalizada: relato de experiência. Revista Intercâmbio, Monte Claros, 238- 243: http://www.intercambio.unimontes.br/index.php/intercambio/article/view/183/197.

Valandro, L. P., Brum, C. N., Potrich, T., Zuge, S. S., Gaio, G., Moraes, C. S., Sabino, V. P., Berlanda, J. B., Coutinho, T. B., Gadonski,R. M., Chiavon S. D., \& Albani, B. (2020). Vivência do cuidador familiar sobre a revelação do diagnóstico da criança com doença oncológica. In S. R. M. Barbosa (Org.), A Enfermagem e o Gerenciamento do Cuidado Integral 7 (pp. 264-276). Atena Editora.: http://dx.doi.org/10.22533/at.ed.69020091224. 